\title{
Urinary Tract Infection Escherichia coli Is Related to the Environmental Escherichia coli in Their DNA Barcoding and Antibiotic Resistance Patterns in Grenada
}

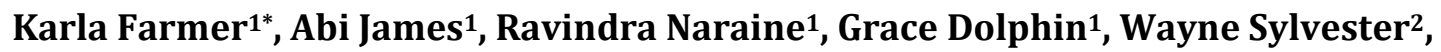 \\ Victor Amadi ${ }^{2}$, Svetlana V. Kotelnikova ${ }^{1}$ \\ ${ }^{1}$ School of Medicine, St. George's University, St. George's, Grenada \\ ${ }^{2}$ School of Veterinary Medicine, St. George's University, St. George's, Grenada \\ Email: "KFarmer@sgu.edu
}

Received 19 November 2015; accepted 23 January 2016; published 26 January 2016

Copyright (C) 2016 by authors and Scientific Research Publishing Inc.

This work is licensed under the Creative Commons Attribution International License (CC BY).

http://creativecommons.org/licenses/by/4.0/

(c) (i) Open Access

\begin{abstract}
Urinary Tract Infections (UTIs) are among one of the most common infections in women, with uropathogenic $E$. coli (UPEC) being involved in $80 \%$ of cases. In addition, $E$. coli exhibits an increasing resistance to broad spectrum antimicrobial agents as well as the subsequent generations of these drugs. The genetic diversity and antibiotic resistance patterns of both clinical and environmental $E$. coli isolates were studied to predict the potential of transmission of organisms and genes for antibiotic resistance from three different major eco-habitats including the gut of iguanas' fresh and marine waters and the human urinary tract. (GTG) ${ }_{5}$ and BOX-PCR extragenic DNA fingerprinting allowed for the tracking of the relatedness of four different ecotype groups. Both DNA fingerprinting methods targeted non-protein coding or exogenous palindromic DNA and demonstrated shared origin and intraspecies level of genomic diversity within the population of the studied bacteria. DNA fingerprinting based on BOX-PCR was less discriminating than the (GTG) $5^{-}$ PCR, and produced five major clades. BOX-PCR analysis indicated that $44 \%$ of the UTI E. coli isolates was comprised within a single clade, therefore it correlated better with ecotype distribution. The (GTG) 5 PCR based co-clustering analysis showed that the clinical isolates appeared to have a closer relationship to iguana $E$. coli isolates than to the fresh and marine water isolates. However, in accordance with the BOX PCR co-clustering analysis, the clinical isolates were most similar to the marine water isolates, followed by the freshwater and iguana $E$. coli isolates. Seventy two percent of antibiotic resistance patterns were shared by the UTI strains with $E$. coli isolated from freshwater, followed by iguana.
\end{abstract}

"Corresponding author.

How to cite this paper: Farmer, K., James, A., Naraine, R., Dolphin, G., Sylvester, W., Amadi, V. and Kotelnikova, S.V. (2016) Urinary Tract Infection Escherichia coli Is Related to the Environmental Escherichia coli in Their DNA Barcoding and Antibiotic Resistance Patterns in Grenada. Advances in Microbiology, 6, 33-46. http://dx.doi.org/10.4236/aim.2016.61004 
Keywords

Exogenous DNA, E. coli, Urinary Tract Infection, UPEC, (GTG)

\section{Introduction}

Although E. coli is typically non-pathogenic, some serotypes may play a significant role in intestinal and urethral diseases, which can be linked to the variety of virulence factors it possesses such as Pili type 1, exopolysaccharides, and hemolysins [1]-[4]. The spread of pathogenic bacteria that are resistant to certain antibiotics constitutes a growing threat to public health. Annually eight million cases of Urinary Tract Infections (UTIs) are recorded in the United States and over 150 million worldwide. Uropathogenic Escherichia coli is the most prominent pathogenic agent resulting in over $80 \%$ of UTI infections [5] [6]. In addition, E. coli exhibits an increasing resistance to broad spectrum antimicrobial agents as well as the subsequent generations of these drugs [7]-[10].

The genetic diversity and genome plasticity of $E$. coli contributes to it pathogenicity, virulence and adaptation [11]. Within a group of clonal populations, a diverse genetic makeup may replicate [12]. Some human hosts display the dominant UPEC strain in both their urine and feces, which are the same throughout all three recurrent UTIs, while other hosts exhibit different $E$. coli clonal adaptation through the recurrent infections [13]. E. coli demonstrated diversity among the different strains in different ecological settings [9].

Enterobacteriaceae are found in a variety of natural habitats including the soil, meats, fruits, waters, vegetables, animals and plants. The research conducted on uropathogenic E. coli showed that it generally originatesfrom the intestinal and rectal biota and enters the bladder through the urethra. There was an observed trade-off of fitness to microbial succession from human urethra to human gut originated strains in re-current UTIs [1]. Manges et al. [14] showed that ExPEC E. coli was genetically related to E. coli isolated from chicken retail meat. Dissemination of antibiotic resistant Enterococcus spp. and E. coli from wild birds of Azores Archipelago was shown [15]. In Grenada, the iguana is a common food source and known carrier of E. coli [16]. However, most of the natural reservoirs of the UTI E. coli are still unknown. It is hypothesized that $E$. coli from environmental sources such as iguana meat, fresh water and coastal sea water is genetically related or identical to clinical isolates of E. coli.

The goal of this study is to identify the genomic elements that can contribute to the diversification and evolution of different species of $E$. coli and also to create a culture collection of $E$. coli from variable sources including urine from patients presenting with symptoms of UTI at St. George's University (SGU) Clinic, iguanas tested at the SGU Small Animal Hospital, coastal seawaters and tropical river freshwater samples collected by the SGU Environmental Testing Unit, all on the southern Windward Island of Grenada in West Indies. The phenotypically identified E. coli isolated from the urine of UTI patients in Grenada was DNA barcoded and statistically compared to the DNA barcodes of environmental isolates of iguana, fresh and marine waters. The DNA barcode variation of clinical and environmental strains was compared to the genomic variations of those isolates. Finally, the antibiotic resistance patterns within the culture collections were analysed and compared.

\section{Materials and Methods}

\subsection{Culture Isolation and Confirmation}

Eighty-five E. coli strains were isolated using double streak plating on eosin methylene blue (EMB) agar (Levine) and Maconkey agar from IRB approved de-identified human urine (25) (Collected over a period of Spring 2005-Spring 2014), iguana (39) (collected in Spring 2013), fresh (11) (Collected in Fall 2013) and marine waters (10) (Collected during the period of Fall 2008 and Spring 2010) in Grenada. Pure cultures of E. coli were obtained by the transfer of single colony using two successive streak plates [17]. This was achieved by streaking the gas producing lactose broth (LB) inoculated with a sample onto an EMB agar plate and incubated at $37^{\circ} \mathrm{C}$ for 18 - 24 hours [18] [19]. To achieve this, samples were inoculated into lactose broth and all tubes were incubated in a shaker bath at $37^{\circ} \mathrm{C}$ for $18-24$ hours. The LB medium tube showing positive growth and carbon dioxide gas as a result of fermentation of lactose within the inverted Durham tubes, were indicative of possible $E$. coli 
isolates. Samples were then taken from these tubes and streaked onto EMB agar. Each colony of possible E. coli isolates that presented as shiny metallic green on EMB agar was isolated and re-streaked onto MacConkey agar. Colonies that produced pink colonies with a pink halo around them was deemed indicative of possible $E$. coli. UTI strains were isolated from the urine of the patients that were admitted to the St. Georges University clinic and presented with symptoms of UTI during the study period. Iguana isolates were collected from living iguanas coats as well as freshwater and marine water from 9 Grenadian parishes [20].

To differentiate E. coli from other Enterobacteriaceae multiple differential tests were used for the preliminary confirmation of the isolates, including the citrate test, the Triple Sugar Iron (TSI) slant, Sulfite Indole Motility (SIM) and indole test. Alkaline carbonates and bicarbonates are produced when citrate is used as a carbon source [21].The TSI test differentiates E. coli based on their fermentation of lactose, glucose and sucrose as well as on the production of Hydrogen Sulphide [22]. Sulfite Indole Motility (SIM) medium is a semisolid agar that is used to determine hydrogen sulfide $\left(\mathrm{H}_{2} \mathrm{~S}\right)$ production, indole formation, and motility. The development of a red color after the addition of Kovács reagent indicates indole production from tryptophan. The result of a black precipitate is an indication of Ferrous Sulfide (FeS) production [22]. Final confirmation of E. coli was performed using the BioMerux API20E strips (www.biomerieux.com).

All positively confirmed strains produced small, dark colonies with a green metallic sheen on the OXOID Levine EMB agar and small red colonies on the BBL MacConkey's Agar. E. coli (ATCC 25922) was used as the control in all confirmation tests.

\subsection{Deoxyribonucleic Acid (DNA) Extraction}

Genomic DNA was extracted from individual pure cultures of E. coli using GenEluteTM Bacterial Genomic DNA Kit (Cat. \# NA2120-1KT) (SIGMA-ALDRICH). The starting product was a single colony of each identified E. coli isolate from the re-streaked EMB/MAC plates that was inoculated in lactose broth and incubated in a shaker bath at $37^{\circ} \mathrm{C}$ for $18-24$ hours. The purity and concentration of the yield DNA was verified by Thermo Scientific NanoDrop 2000 Spectrophotometer. The DNA aliquots were stored at $2^{\circ} \mathrm{C}-8^{\circ} \mathrm{C}$ for short term storage (less than 30 days), and then transferred to $-80^{\circ} \mathrm{C}$ for a long-term. Utilizing the Nanodrop the isolate's DNA concentrations were standardized to $11.3 \mathrm{ng} / \mu \mathrm{l}$ for each isolate.

\subsection{DNA Barcoding}

The isolates were compared using a combination of (GTG) $)_{5}$ PCR and BOX-PCR extragenic DNA fingerprinting. BOX-PCR (primer, BOX A1R); and (GTG) $)_{5}$-PCR (primer (GTG) $)_{5}$ ), are commonly used for genotyping of different E. coli strains [23] [24].

\subsection{PCR Protocol}

All PCR reactions were performed utilising Pre and Post-PCR rooms which were disinfected with $75 \%$ ethanol and 10\% bleach and Stratagene Agilent Mx3005P Thermal cycler. All biological materials were disposed into the appropriate biohazard containers after autoclaving.

The Rep-PCR amplification was performed in accordance with the previously described method by Versalovic et al 1994 [23] [25]. The reaction mixtures (25 $\mu \mathrm{L})$ used for BOX-PCR and (GTG) $5_{5}$-PCR were prepared using 50 ng template DNA, $2 \mu$ M primers and $12.5 \mu \mathrm{L}$ EmeraldAmp GT PCR Master Mix (Takara, \# RR 310 B). The positive control used was the Escherichia coli ATCC 25922. The PCR amplification was performed using following thermal cycling program: denaturation for 2 mins at $95^{\circ} \mathrm{C}, 30$ cycles of annealing consisting of $3 \mathrm{sec}$ at $94^{\circ} \mathrm{C}, 30 \mathrm{sec}$ at $92^{\circ} \mathrm{C}, 1 \mathrm{~min}$ at $40^{\circ} \mathrm{C}$, and $8 \mathrm{~min}$ at $65^{\circ} \mathrm{C}$, followed by extension for $8 \mathrm{~min}$ at $65^{\circ} \mathrm{C}$.

\subsection{Gel Electrophoresis}

Species or strain DNA specific patterns were obtained utilizing separation of the DNA resulting from the PCR reactions by using $1.5 \%$ agarose gel electrophoresis at $105 \mathrm{~V}$ for 4 hours and 20 minutes. The agarose gel was prepared by adding $1.8 \mathrm{~g}$ of Ultra-Pure TM Agarose (\#15510 - 019, Invitrogen, Carlsbad, Ca, USA) to $120 \mathrm{ml}$ of 1x TBE EDTA buffer. Fifty millilitres of molten agarose were poured into the electrophoresis tray to create a $0.5 \mathrm{~cm}$ thick gel. The gel comb was inserted to create 20 wells in the gel. The running chamber of the Thermo Scientific ${ }^{\mathrm{TM}}$ Owl ${ }^{\mathrm{TM}}$ Easy Cast ${ }^{\mathrm{TM}}$ B2 Mini Gel Electrophoresis Systems was filled with $800 \mathrm{ml}$ 1X TBE buffer to 
the electrophoresis kit until the liquid covered the gel completely. Five microliters (5 $\mu \mathrm{l})$ of GeneRuler $1 \mathrm{kbp}$ DNA Ladder, Ready- to-use, 75 - 20,000 bp. (\#, FERSM1333, Fermentas USA) was mixed with $1 \mu \mathrm{l} 6 \mathrm{X}$ loading dye and $5 \mu \mathrm{l}$ of was loaded in lane 1 of the gel. Five microliters $(5 \mu \mathrm{l})$ of each standardized PCR-product DNA samples were loaded into each well. The control of $E$. coli ATCC strain was loaded into each gel as an internal normalization control. The gel was then stained by soaking in $800 \mathrm{ml}$ of $1.0 \mu \mathrm{g} / \mathrm{ml}$ Ethidium Bromide (EtBr) for 45 minutes. The gel was then de-stained by soaking in $800 \mathrm{ml}$ distilled water for 10 minutes. The gels were visualized by using a UVP UV Transilluminator and the resulting image was documented using Olympus Tough TG-830 iHS camera.

The DNA barcode of each isolate were compared using a combination of (GTG) 5 PCR and BOX-PCR extragenic DNA fingerprintingon agarose gels. DNA amplicons that originated from different gels were manually normalized against E. coli K12 (ATCC 25922) using Microsoft Excel 2013 as the E. coli K12PCR replication product was used as an internal control during each gel DNA band separation.

\subsection{Phylogenetic Analysis}

Cluster analysis was performed using UPGMA (Unweighted Pair Group Method with Arithmetic Mean) as the clustering algorithm and Pearson product-moment correlation coefficient. This was performed using Dendro UPGMA: a dendrogram construction utility [26] http://genomes.urv.cat/UPGMA/index.php?entrada=Example2. The Pearson coefficient was selected and submitted and the output dendrogram in Phylip format was then exported into FigTree ${ }^{\mathrm{TM}}$ version 1.4.2 [27] and visualized.

\subsection{Statistical Analysis of DNA Patterns}

The strains were grouped into the four ecotypes in accordance with the source of isolation and designated as Clinical (C), Iguana (I), Marine (M) and Freshwater (F). Distribution of ecotypes of E. coli among the established REP phylotypes was calculated using the number of strains that belonged to an ecotype per clade against the total number of strains per ecotype. The differences in proportion and distribution of the fragments were assessed using the Pearson's coefficient. Co-clustering and cluster dominance analysis of strains were performed using dendrograms based on (GTG) ${ }_{5}$ and Box analysis.

Quantification of the number of strains co-clustering between their own phylotype or clade will hereon be referred to as co-clustering analysis and was assumed that the co-clustered strains were genetically related. Coclustering of the most closely related pairs which belong to the same phylotype was analyzed under assumption that those isolates appeared to be evolutionary related to each other as a result of the high variation of non-coding DNA which has been targeted by this analysis.

Clade dominance distribution among the phylotypes was calculated using the number of each ecotype in the clade against the total number of isolates in the clade.

Correlation analysis between the numbers of bands observed per isolate in the DNA fingerprint and the number of antibiotic resistances was performed using correlation analysis in MicrosoftEXCEL 2013.

\subsection{Genomic Variation}

The full genomic statistical data for 1194 of E. coli strains isolated from clinical and non-clinical sources were downloaded from the publicly available IMG JGI Department of Energy Institute Database (https://img.jgi.doe.gov) and analysed. Variants for each genomic element identified were compared after separating the genomes to clinical and environmental groups of $E$. coli by their origin.

\subsection{Antibiotic Resistance}

After the inoculation of each plate six different antimicrobial disks were placed onto the plate surface, using the 6-place stamping disks dispenser (BBL ${ }^{\mathrm{TM}}$ Sensi-Disc ${ }^{\mathrm{TM}}$, USA. Cat\#. 260661) as described by [28] [29]. The dispenser was loaded with six antimicrobial cartridges each containing the individual antimicrobial disks and placed onto the inoculated plate following the manufacturer's instruction (BD BBLTM, 2006). After the disks were placed onto the plate, the plate was covered, inverted, and incubated for 18 to 24 hours [28]. The diameters of the complete zones of inhibition were measured to the nearest millimeter using a standard measuring ruler as described by [28] [29]. The zone diameters of the duplicates and their averages were recorded and used to determine whether the organism was resistant (R), intermediate (I), or susceptible (S), to the tested antimicrobial 
based on the zone diameter interpretive chart provided by the BD BBL TM Sensi-Disc Antimicrobial Susceptibility Test Discs, adapted from the CLSI (BD BBLTM, 2007a).

\subsection{Statistical Analysis of Resistance Patterns}

Multidrug resistance was calculated as resistance to 2 or more antibiotics. The percentage of isolates that exhibit Multidrug Resistance (MDR) and Single Drug Resistance (SDR) was calculated as the number of those that were multidrug resistant against the total number of ecotype isolates. The percentage of the ecotypes that demonstrated resistance or intermediate resistance per antibiotic tested was achieved by using the total number of ecotypes demonstrating resistance or intermediate resistance per antibiotic against the total number of strains in the ecotype.

To observe the similarity or dissimilarity of the antibiotic patterns observed per ecotype the t-test using the diameter of the zone of clearance per antibiotic per ecotype analyzed against the zone of clearance of the same antibiotic in a different ecotype. The dissimilarity of the antibiotic resistance patterns observed between each ecotype was calculated as a percentage utilizing the number of antibiotics that were deemed insignificant $(\mathrm{p}<$ 0.05) against the total number of antibiotics observed with those ecotypes.

To observe the similarity or dissimilarity of the antibiotic patterns observed per ecotype to their DNA profiles the correlation analysis was utilized. Statistica ${ }^{\mathrm{TM}}$ data analysis software was used [30].

\subsection{Statement of the SGU IRB Approval of the Study}

The study was reviewed and approved by the St. Georges University Institutional Review Board, which indicated that material relating to human investigations and animal experiments conforms to standards currently applied in the country of Grenada where the study has been performed.

\section{Results}

All isolates included in the DNA fingerprinting analysis were represented by pure cultures and were confirmed to possess phenotypes of $E$. coli in accordance with the criteria described above. The isolates which did not present the phenotype of $E$. coli were excluded from the consequent analysis.

In compliance with Dendro UPGMA comparison of DNA fingerprints based on the Pearson's coefficient, and co-clustering analysis it was found that 52\% (GTG) and $44 \%$ (BOX) of clinical UTI E. coli isolates were related to iguana E. coli isolates, in accordance with Figure 1 and Figure 2, respectively. Freshwater isolates shared (GTG) 5 DNA marker based patterns with marine E. coli and UPEC (Table 1). The (GTG) 5 DNA markers of wild green iguana isolates were similar to E. coli from UTI urines and from freshwater. The BOX DNA markers of $E$. coli isolated from both fresh and marine waters were related to UPEC.

The BOX dominance analysis demonstrated that there was similarity in the DNA fingerprints between the clinical and marine waters isolates (Figure 2).

The analysis showed that the majority (28\%) of UTI E. coli was comprised within clade 1 (Figure 2). The remaining strains were distributed throughout five other major phylotypes. Remarkably, clinical UTI isolates were present in all 7 clades, indicating a potential relatedness to the isolates from natural habitats. Most of them were distributed among clades AI-1, AII-4 and BII-7. Iguana isolates dominated AI-1, AI-2 and BI-5 and were absent only in clade BII-6. Most of Freshwater isolates were in the cluster AI-1, which comprised majority of clinical, iguana and marine isolates, therefore nominated as the most common clade representing Grenadian $E$. coli and were absent in cladesAI-2, AII-3and BI-6.

The isolates from the fresh water ecotype grouped with another fresh water isolate on the nearest adjacent leaf of the Dendrogram tree twice (2 isolates). In total the ecotype to ecotype grouping was 36 of the total 83 isolates (43.4\%).

The BOX DNA fingerprinting demonstrated two major groups: group A and group B (Figure 2). Group B subsequently branched off into B1 and B2. Clade A branched off into 2 subgroups: a small subgroup called A2 and a larger subgroup called A1. Eventually A1 evolved into 2 more subgroups called X and Y. The strains were distributed throughout five major phylotypes.

The analysis showed that the majority of the UTI E. coli isolates were comprised within clades: A1-X (52\%), A1-Y (44\%) and B2. Clinical UTI isolates were present in only 3 out of 5 clades, thus they were more closely related to another clinical stains, rather than to marine water, iguana or fresh water E. coli isolates. 

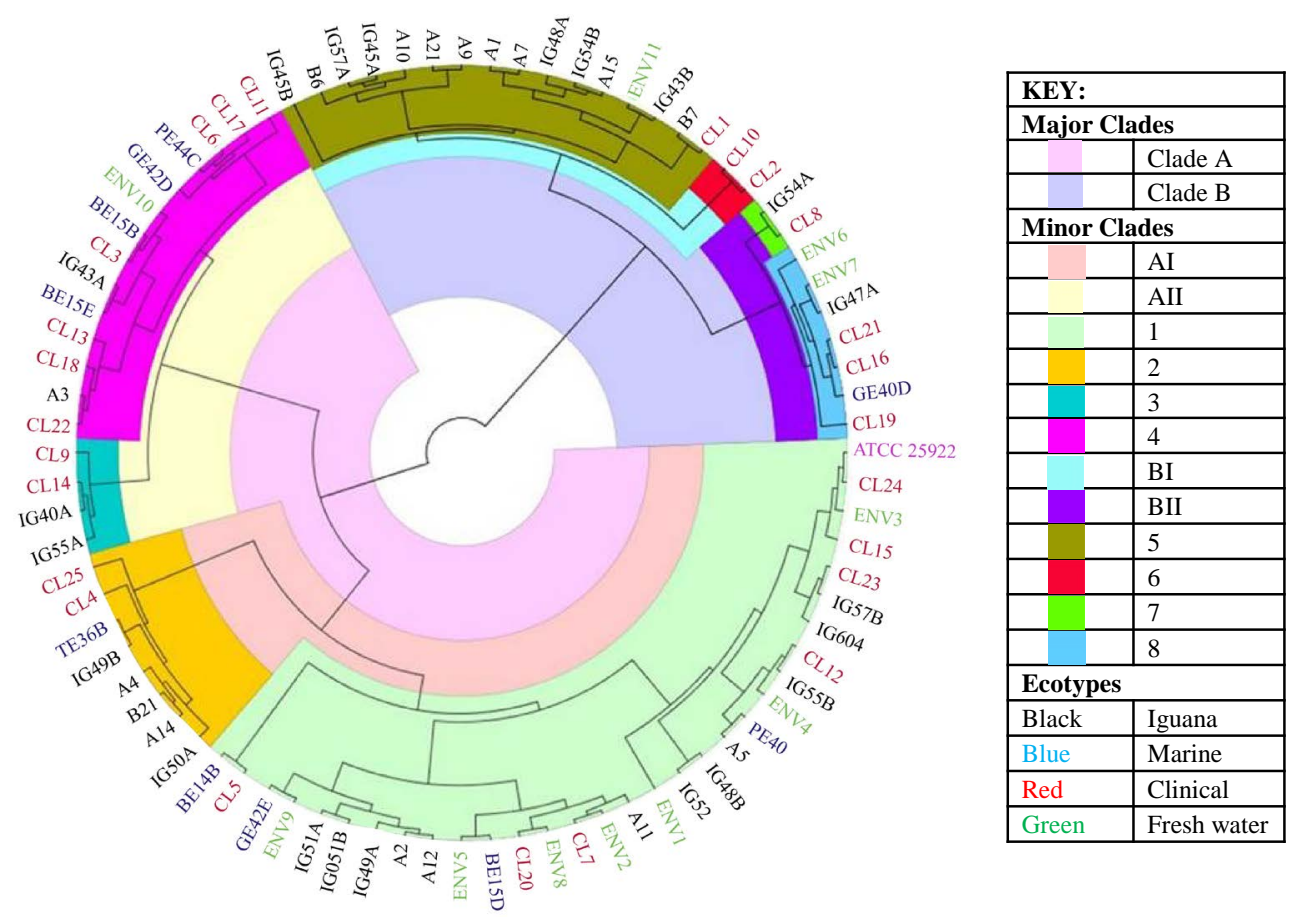

Figure 1. Unrooted neighbor joining dendrogram based on (GTG)5 analysis. Major clades: Clade A (pink) and Clade B (grey-hued purple). AI (peach), AII (light yellow), 1 (light green), 2 (golden yellow), 3 (teal), 4 (bright pink), BI (light blue), BII (purple), 5 (moss green), 6 (red), 7 (bright green), 8 (blue). Ecotypes: iguana (black), marine isolates (blue), clinical isolates (red), fresh water isolates (green).

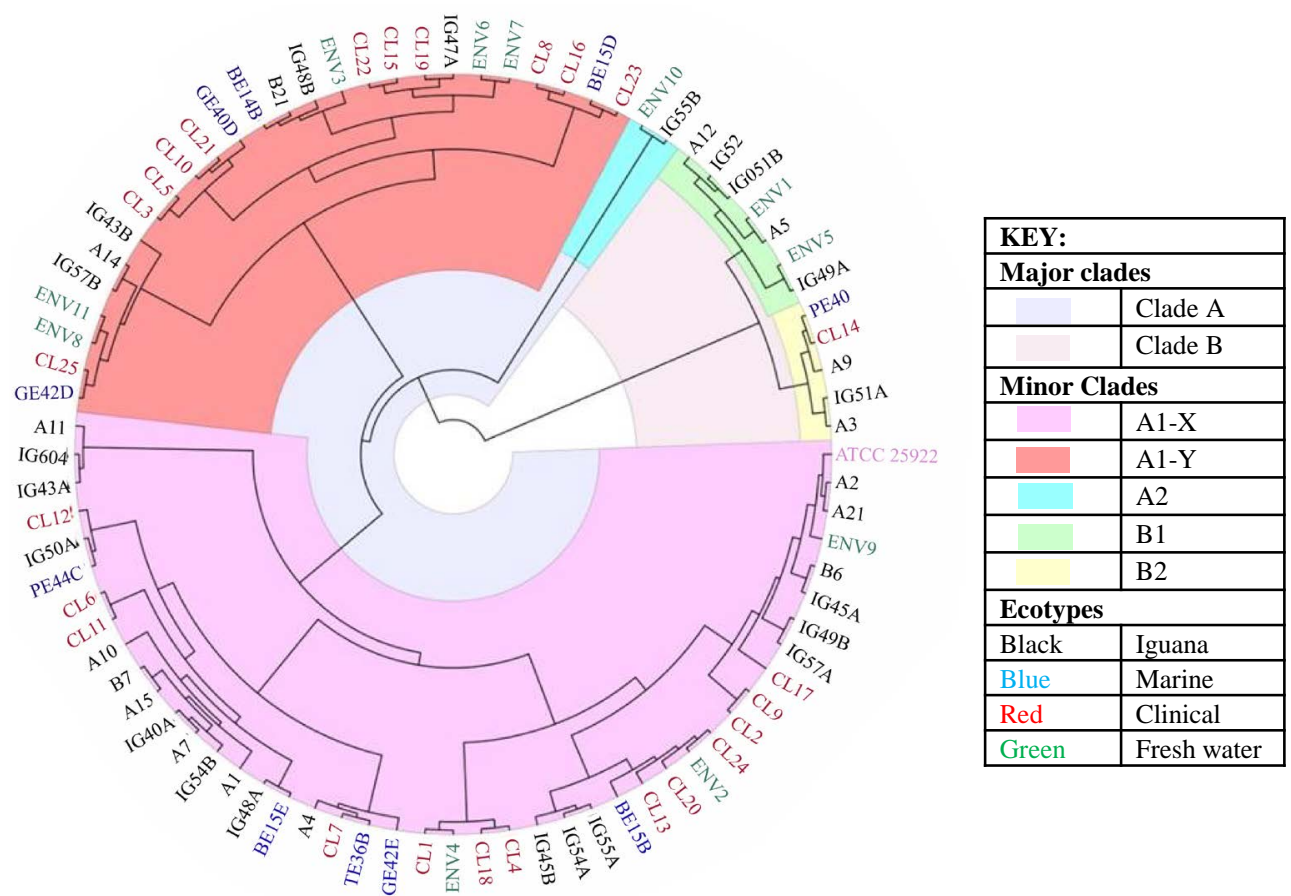

Figure 2. Unrooted neighbour joining dendrogram based on BOX PCR. Major clades: Clade A (light purple) and Clade B (light peach). Minor clades: A1-X (pink), A1-Y (red), A2 (teal), B1 (green), B2 (yellow). Ecotypes: iguana (black), marine isolates (blue), clinical isolates (red), fresh water isolates (green). 


\subsection{Co-Clustering Analysis of Closely Related Pairs}

The (GTG) $)_{5}$ PCR based co-clustering analysis of the phylogenetic tree in Figure 1 indicated that the clinical isolates had a closer relationship to iguana $E$. coli isolates (36\% of closely related pairs) than to fresh (14\%) and marine (29\%) water isolates. However, in accordance with the BOX PCR analysis, 50\% of clinical isolates paired with human isolates while the rest were most similar to marine (29\%), followed by freshwater (14\%) and iguanas (7\%), The next leaf co-clustering relatedness analysis of the (GTG) $)_{5}$ and BOX dendrograms confirmed the results of the fingerprinting of dominating ecotypes, indicating that clinical isolates were most often related to the iguana isolates (source of food in Grenada), and to the marine E. coli.

\subsection{Is REP PCR Banding Reflective of Intraspecies Genomic Diversity?}

The variation and comparison of numbers of bands per strain in the (GTG) $)_{5}$-PCR and BOX DNA fingerprints are shown in Table 2. Table 2 demonstrated that the variation of the numbers of bands observed in the (GTG) $5^{-}$ PCR resulted in $10.2 \%$ of the average while the BOX PCR analysis resulted in $18 \%$ of the average.

As shown in Table 3, there was greater variance observed in the banding pattern of each ecotype in accordance

Table 1. Shared ancestry of $E$. coli strains from different environments based on dominance analysis.

\begin{tabular}{|c|c|c|c|c|c|}
\hline Percent of shared ancestry & UPEC & Iguana & Fresh water & Seawater & Top similarity \\
\hline UPEC & $\mathrm{GTG}_{5}$ & 52 & 36 & 48 & Iguana \\
\hline UPEC & $\mathrm{BOX}$ & 44 & 28 & 56 & Seawater \\
\hline Iguana & 41 & $\mathrm{GTG}_{5}$ & 31 & 28 & UPEC \\
\hline Iguana & 28 & $\mathrm{BOX}$ & 49 & 15 & Fresh water \\
\hline Fresh water & 63 & 55 & $\mathrm{GTG}_{5}$ & 72 & Seawater \\
\hline Fresh water & 72 & 36 & $\mathrm{BOX}$ & 27 & UPEC \\
\hline Marine water & 80 & 30 & 40 & $\mathrm{GTG}_{5}$ & UPEC \\
\hline Marine water & 80 & 70 & 30 & $\mathrm{BOX}$ & UPEC \\
\hline
\end{tabular}

Table 2. Comparison of (GTG) ${ }_{5}$-PCR and BOX DNA fingerprints.

\begin{tabular}{|c|c|c|c|c|c|c|c|c|}
\hline & $\begin{array}{c}\text { \# of strains } \\
\text { analyzed }\end{array}$ & $\begin{array}{l}\text { Range of } \\
\text { REP bands }\end{array}$ & $\begin{array}{l}\text { ATCC } \\
\text { Strain \# } \\
\text { of bands }\end{array}$ & $\begin{array}{l}\text { Average } \\
\text { number of } \\
\text { REP bands }\end{array}$ & $\begin{array}{c}\text { Variance } \\
\text { among } \\
\text { isolates }\end{array}$ & $\begin{array}{c}\text { SD } \\
\% \text { of } \\
\text { average }\end{array}$ & $\begin{array}{c}\text { Variance among } \\
\text { solates } \\
\text { excluding the } \\
\text { ATCC strain }\end{array}$ & $\begin{array}{l}\text { SD of strains } \\
\text { excluding } \\
\text { ATCC strain }\end{array}$ \\
\hline$(\mathrm{GTG})_{5}$ & 83 & $22-36$ & 39 & 27 & 9.07 & $\begin{array}{c}3.01 \\
11.2 \%\end{array}$ & $\begin{array}{c}7.53 \\
27.8 \%\end{array}$ & $\begin{array}{c}2.74 \\
10.2 \%\end{array}$ \\
\hline BOX & 83 & $15-34$ & 28 & 22 & 15.85 & $\begin{array}{c}3.98 \\
18.1 \%\end{array}$ & $\begin{array}{l}15.63 \\
71 \%\end{array}$ & $\begin{array}{c}3.95 \\
18.0 \%\end{array}$ \\
\hline
\end{tabular}

Table 3. Summary table of banding patters per ecotype in accordance with (GTG) 5 -PCR and BOX-PCR.

\begin{tabular}{|c|c|c|c|c|}
\hline \multicolumn{5}{|c|}{$(\mathrm{GTG})_{5}$-PCR: } \\
\hline Ecotype & Number of bands & Average number of bands & SD & Variance \\
\hline Clinical & $22-36$ & 28.04 & 3.48 & 12.12 \\
\hline Iguana & $22-31$ & 26.75 & 2.27 & 5.16 \\
\hline Freshwaters & $24-36$ & 27.54 & 3.14 & 9.87 \\
\hline Marine waters & $25-29$ & 27.4 & 1.26 & 1.6 \\
\hline \multicolumn{5}{|c|}{ BOX-PCR: } \\
\hline Ecotype & Number of bands & Average number of bands & $\mathrm{SD}$ & Variance \\
\hline Clinical & $16-30$ & 22.16 & 8.27 & 68.36 \\
\hline Iguana & $17-32$ & 22.64 & 5.20 & 19.34 \\
\hline Freshwaters & $18-34$ & 22.46 & 3.88 & 15.03 \\
\hline Marine waters & $15-28$ & 22.3 & 3.40 & 11.57 \\
\hline
\end{tabular}


with the BOX-PCR than the variance observed in the banding pattern of the ecotypes in the (GTG) $)_{5}-\mathrm{PCR}$. Variation among the clinical strains, both detected by $(\mathrm{GTG})_{5}$ and Box PCR, exceeded all other kinds of ecotypes, confirming its polyphyletic relatedness.

Table 4 was compiled utilizing the genomic information obtained from the Integrated Microbial Genome database (IMG). The variation observed in this experiment was compared with the variation of multiple genetic elements in previously sequenced genomes of 1194 strains of $E$. coli, which are available online. This study demonstrated that the E. coli genome of 1194 clinical strains of $E$. coli was on average of 5173036 bp with a standard deviation of $288811 \mathrm{bp}$.

The analysis of the genomes of human E. coli strains, in this study, showed that most of the genome variation was due to the variation of number of pseudogenes (609\%), of numbers of CRISPRs (278\%) and horizontally transferred genes per genome (162\%) (Table 4). Variation due to the number of genetic elements including variation in number of fused genes (48\%), in number of RNA-coding genes (56\%), in number of proteins with signal peptides (10\%), in number of gene duplications (8.2\%), in number of gene fusions (3.5\%) and number of bacteriophages (1.12\%) per individual genome indicated contribution of these genetic elements to the host induced evolution of human E. coli. Remarkably, all genes annotated were arranged as gene cassettes in all strains sequences.

Of all the sequenced genomes, only 6 UPEC genomes were sequenced and analyzed. Based on this compiled information, the UPEC genome was 5,116,773 bp, which was close to the average size of the genome in human intestinal strains. This corresponds to the typical E. coli genome listed in Table 4, however the standard deviation observed was only 2.7 percent indicating less variation in size of genome than in most of the sequenced human E. coli (5.56\%). In the UPEC genome, variation due to the number of horizontally transferred genes per genome was $36.5 \%$.

Within the UPEC strains only, variation in the number of of CRISPRS (155\%), pseudogenes (82\%), genes subjected to horizontal transfer (36.5\%), RNA-coding genes (3.6\%), gene duplications (2.7\%), and, finally, gene fusions (7.3\%) per an individual genome, indicated typical but less significant contributions of these genetic elements than for intraspecies variation among 1194 strains. This also might indicate a specialization of UPEC due to the host induced evolution. It was observed that the size of the group subjected to the analysis of variation affected the level of variation in numbers of all genetic elements tested.

Discrimination level of DNA barcoding allowed to follow the relatedness or common origin of individual strains which belong to the different ecotypes. In this DNA barcoding experiment wide intraspecies genetic diversity of exogeneous DNA with variation typical and comparable to genomic variation due to a number of genomic elements typical for the species based on 1194 individual genomes of human originated E. coli was observed.

Table 4. Summary of the compiled genomic data for 1194 E. coli strains isolated from human skin, feces and urine and sequenced by the Joint Genome Institute Database (JGI-IMGACT).

\begin{tabular}{|c|c|c|c|}
\hline E. coli & Average & Standard deviation (SD) & Percentage of SD out of the average (\%) \\
\hline Genome size (base pairs) & $5,173,036$ & $288,811.4$ & 5.58 \\
\hline Gene Count & 5213 & 432 & 8.1 \\
\hline CRISPR Count & 0.32 & 0.89 & 278 \\
\hline GC content, \% & 50.57 & 0.5 & 5.55 \\
\hline RNA genes, \% & 15.83 & 8.83 & 55.6 \\
\hline Pseudo Genes, \% & 0.09 & 0.56 & 609 \\
\hline Genes Paralogs, \% & 70.55 & 5.80 & 8.2 \\
\hline Fused genes, \% & 3.19 & 1.55 & 48 \\
\hline Horizontally transferred genes \% & 0.17 & 0.12 & 162 \\
\hline Signal peptide, \% & 8.45 & 0.85 & 10.17 \\
\hline Genes in cassettes, \% & 100 & 0.02 & 0.003 \\
\hline
\end{tabular}




\subsection{Comparison of Antibiotic Resistance Patterns}

Resistance patterns for the studied groups of E. coli are shown in Table 5. Clinical E. coli were susceptible only to two drugs including ciprofloxacin and gentamicin. This result corresponded with previous studies conducted [30].

\subsection{Comparison of Resistance Profiles}

The E. coli isolates collected and analyzed presented some similarities among their antimicrobial multidrug resistance profiles. In this research multidrug resistant strain was defined as an isolate which presented the resistance to 2 or more antibiotics. Forty eight percent of UPEC were resistant to at least one antibiotic, $16 \%$ were single drug resistant (SDR) while 32\% were multidrug resistant (MDR). About 3\% of iguanas (SDR 18\%), 20\% of marine (SDR 10\%) and 64\% of freshwater (none SDR) were multidrug resistant (Table 6).

There were only three drugs which showed a significant difference in patterns of antibiotic resistance between the clinical isolates and the freshwater isolates, namely for AM $(p=0.045)$, AMC $(p=0.007)$ and F/M $(p=$ 0.004) (Table 7).There were only three drugs which showed significant difference between patterns of resistance between groups of clinical and freshwater isolates, namely for AM (0.003), CB (p = 0.000) and SXT $(\mathrm{p}=$ 0.011). There were three drugs which showed a significant difference between patterns of resistance between the clinical and marine water isolates, namely for TE $(p=0.019)$, AM $(0.015)$ and GM $(p=0.001)$. All ecotypes displayed dissimilarity of resistance patterns to AM apart from the iguana isolates and the marine waters isolates. All compared isolates showed the same patterns of resistance in relation to CIP, CF, NA and CFM. In accordance with t-test analysis of resistant/susceptible patterns among four ecotypes (Table 7) the most similar patterns (83.3\%) were observed between freshwater and marine water isolates, as well as in marine and iguana isolates. Clinical E. coli was 50 percent of strains/resistance patterns were similar to marine and $72 \%$ both to iguana and fresh water isolates.

\section{Discussion}

This study targeted comparison of UPEC to its environmental relatives based on intraspecies exogenous DNA variation and phenotypic antibiotic resistance patterns. Traditional methods to classify bacteria are serotyping, phage typing, microscopy, substrate utilization screening, multilocus enzyme electrophoresis (MLEE), fatty acid methyl ester analysis (FAME), 16S RNA sequence comparison, DNA-DNA hybridization and multi locus sequence typing (MLST). Additionally, antibiotic resistance profiling may be performed using the DNA profile. However, these techniques require pure cultures of the bacteria, target a limited number of genes or proteins and

Table 5. Percentages of resistance strains and fraction of ineffective drugs per an ecotype of $E$. coli studied.

\begin{tabular}{ccccccccccccc}
\hline Resistant & AM & CB & CF & AMC & CFM & TE & CIP & GM & STX & NA & F/M & Drugs* \\
\hline Clinical (25) & $32 \%$ & $36 \%$ & $8 \%$ & $8 \%$ & $8 \%$ & $24 \%$ & 0 & 0 & $16 \%$ & $8 \%$ & $16 \%$ & $82.2 \%$ \\
Iguana (39) & $3 \%$ & $3 \%$ & $18 \%$ & 0 & $3 \%$ & 0 & 0 & 0 & 0 & 0 & 0 & $36.4 \%$ \\
Freshwater (11) & $55 \%$ & $45 \%$ & $45 \%$ & $18 \%$ & $27 \%$ & $18 \%$ & 0 & $9 \%$ & $18 \%$ & $8 \%$ & $9 \%$ & $90.9 \%$ \\
Seawater (10) & $20 \%$ & 0 & $20 \%$ & $10 \%$ & 0 & $10 \%$ & $10 \%$ & 0 & 0 & 0 & 0 & $45.1 \%$ \\
\hline
\end{tabular}

AM, Ampicillin; CB, Carbenicillin; CF, Cephalothin ; AMC, AMOX/Clavulanate; CFM, Cefixime TE, tetracycline; CIP, Ciprofloxacin; GM, Gentamicin; STX, Trimethoprim/sulfamethoxazole; NA, Nalidixic acid; F/M, Nitrofurantoin. *-fraction of inefficient drugs to which bacteria were showing resistance.

Table 6. The percentage of multiple and single drug resistant Escherichia coli strains isolated from variable sources in Grenada in 2013.

\begin{tabular}{cccc}
\hline & MDR (\%) & SDR (\%) & No Resistance (\%) \\
\hline Clinical $(\mathrm{n}=25)$ & $8(32 \%)$ & $4(16 \%)$ & $13(52 \%)$ \\
Iguana $(\mathrm{n}=39)$ & $1(3 \%)$ & $7(18 \%)$ & $31(79.5 \%)$ \\
Fresh $(\mathrm{n}=11)$ & $7(64 \%)$ & 0 & $4(36 \%)$ \\
Marine $(\mathrm{n}=10)$ & $2(20 \%)$ & $1(10 \%)$ & $7(70 \%)$ \\
\hline
\end{tabular}


Table 7. T-test for antibiotic resistance patterns and ecotypes.

\begin{tabular}{|c|c|c|c|c|c|c|c|c|c|c|c|c|c|}
\hline T-test & $\mathrm{TE}$ & $\mathrm{AM}$ & CIP & CB & CF & GM & AMC & NA & $\mathrm{F} / \mathrm{M}$ & CFM & SXT & $\begin{array}{l}\text { Dissimilarity } \\
\text { of antibiotic } \\
\text { resistance } \\
\text { pattern }\end{array}$ & $\begin{array}{l}\text { Similarity } \\
\text { of } \\
\text { antibiotic } \\
\text { resistance } \\
\text { pattern }\end{array}$ \\
\hline $\begin{array}{l}\text { Clinical } \\
\text { vs } \\
\text { Fresh } \\
\text { Water }\end{array}$ & $0.303^{*}$ & 0.045 & 0.352 & 0.379 & 0.311 & 0.746 & 0.007 & 0.456 & 0.004 & 0.171 & 0.652 & $\begin{array}{l}3 \text { of } 11 \\
\text { (27.3\%) }\end{array}$ & $\begin{array}{l}8 \text { of } 11 \\
(72.7 \%)\end{array}$ \\
\hline $\begin{array}{l}\text { Clinical } \\
\text { vs } \\
\text { Iguana }\end{array}$ & 0.051 & 0.003 & 0.011 & 0.000 & 0.487 & 0.401 & 0.235 & 0.873 & 0.279 & 0.461 & 0.011 & $\begin{array}{l}3 \text { of } 11 \\
(27.3 \%)\end{array}$ & $\begin{array}{l}8 \text { of } 11 \\
(72.7 \%)\end{array}$ \\
\hline $\begin{array}{l}\text { Fresh } \\
\text { Water } \\
\text { vs } \\
\text { Iguana }\end{array}$ & 0.891 & 0.000 & 0.379 & 0.002 & 0.156 & 0.513 & 0.001 & 0.311 & 0.009 & 0.238 & 0.058 & $\begin{array}{l}4 \text { of } 11 \\
(36.36 \%)\end{array}$ & $\begin{array}{l}7 \text { of } 11 \\
(63.6 \%)\end{array}$ \\
\hline $\begin{array}{l}\text { Clinical } \\
\text { vs } \\
\text { Marine } \\
\text { Waters }\end{array}$ & 0.019 & 0.015 & 0.074 & & 0.681 & 0.001 & 0.648 & & & & & $\begin{array}{l}3 \text { of } 6 \\
(50 \%)\end{array}$ & $\begin{array}{l}3 \text { of } 6 \\
(50 \%)\end{array}$ \\
\hline $\begin{array}{l}\text { Fresh } \\
\text { Water } \\
\text { vs } \\
\text { Marine } \\
\text { Waters }\end{array}$ & 0.211 & 0.000 & 0.150 & & 0.265 & 0.072 & 0.217 & & & & & $\begin{array}{l}1 \text { of } 6 \\
(16.67 \%)\end{array}$ & $\begin{array}{l}5 \text { of } 6 \\
(83.3 \%)\end{array}$ \\
\hline $\begin{array}{l}\text { Marine } \\
\text { Waters } \\
\text { vs } \\
\text { Iguana }\end{array}$ & 0.115 & 0.319 & 0.234 & & 0.787 & 0.024 & 0.419 & & & & & $\begin{array}{l}1 \text { of } 6 \\
(16.7 \%)\end{array}$ & $\begin{array}{l}5 \text { of } 6 \\
(83.3 \%)\end{array}$ \\
\hline
\end{tabular}

*T-test P coefficient indicates lack of statistically significant difference unless it is smaller than 0.05 .

can be extremely time consuming. However, both the 16S RNA sequence comparison and DNA-DNA hybridization cannot resolve the intraspecies diversity. The 16S RNA method could be used for the identification of environmental strains as $E$. coli species provided that species definition is based on a single gene [31].

The phylogenetic relationships among strains can be determined by pulsed-field gel electrophoresis [32], ribotyping [33] [34], ribosomal DNA heterogeneity analysis [35], and repetitive extragenic palindromic-PCR (rep-PCR) [36]. However, the use of another DNA fingerprinting method, rep-PCR [36] has been reported as a more accurate mean of $E$. coli strain identification [25]. Previous genetic diversity studies indicated potential for transmission of food-borne and water-borne E. coli strains or resistances to human patients [6] [25] [37] [38]. However the analysis of the serotypes, pathogenicity and virulence of E. coli culture collection relied only on few genes that may be subjected to horizontal gene transfer. Therefore the phenotypic identification of the isolates to the species of $E$. coli was chosen.

The co-clustering of the most closely related pairs which belong to the same phylotype were analyzed under assumption that those isolates appeared to be evolutionary related to each other as a result of the high variation of non-coding DNA which has been targeted by this analysis. This study of genetic diversity of clinical and non-clinical E. coli in Grenada using the (GTG) $)_{5}$ analysis demonstrated that the clinical strains displayed similarity to the iguana isolates. Almost $1 / 3$ of the clinical isolates were similar to marine isolates as they grouped in pairs as shown using both the (GTG) $)_{5}$ and BOX DNA fingerprinting analysis, presenting high similarity in the variable part of the genome. The (GTG) $)_{5}$ and BOX DNA fingerprinting primers targeted different types of exogenous DNA therefore they produced the phylogenetic trees of different topology, however both methods allowed to reveal the intraspecies diversity and relationships. Observation of a high number of genetically similar strains between clinical urine samples from humans and the seawater in this study agreed with observations made by of previous research [39] [40]. This might have been as a result of urination in the beach water and the subsequent survival of the osmotolerant $E$. coli strains which agreed with [40] [41], a link which requires further investigation. 
The pool of these strains both in fresh and marine water may also be a potential reservoir for transmission of MDR genes in attached microbial communities and possibly infection of and among the bathing individual [39] [42] [43].

This study compared the resistance patterns in UPEC to those in E. coli isolated from aquatic natural environments and iguana around Grenada. Similar antibiotic resistance patterns in UPEC and strains isolated from iguana, freshwater and marine coastal surface water (Table 5) was observed in this report. The types of resistance overlapped among different ecotypes. As noted in Table 6 there are some multi drug resistance (MDR) and single drug resistance (SDR) among the clinical isolates. The percentage of MDR strains in this investigation was similar to the percentage observed by Amadi et al., 2012 [39] [40]. Thus, this may indicate that there is possible sewage pollution of marine and freshwater in Grenada which agrees with earlier observations of Patel et al., 2008 [44].

Resistance profiles did not correlate to the DNA barcode based grouping which agreed with earlier studies [45] [46], however, antibiotic resistant E. coli has previously been observed in wild animals [47] [48].

As a result of $E$. coli's genetic flexibility and adaptability to survive in diverse stressful conditions, both commensal and pathogenic E. coli strains have the ability to survive in terrestrial and aquatic habitats [41]. In the past decade attention has been paid to resistant $E$. coli in marine environments as well as on migratory birds specifically pertaining to the increasing indication of their possible role in the spreading of antibiotic resistant Enterobacteriaceae, particularly Escherichia coli [15] [25] [39] [48] [49].

The information obtained from this research is important as it identified relatedness of environmental isolates of $E$. coli in water and wild animals with UTI E. coli and their resistance patterns showed significant similarity. The newly created culture collection can be used to sequence the full genomes of the organisms for future comparative research as well as to identify the origin genes for the antibiotic resistance in the strains of $E$. coli from four different environments, visualize genome based means of intra-species genetic diversity of $E$. coli and to compare the drug resistance between them.

Furthermore, serotyping for the $\mathrm{O}$ and $\mathrm{H}$ antigen can be used to compare the culture collection created $E$. coli with other known bio-geographically affiliated E. coli from other parts in the world. Additionally, if full sequence analysis is performed on the created culture collection it can allow for biogeographic comparison and identification of genes responsible for the observed antibiotic resistance. Further information can also be gathered from the created culture collection by performing PCR on these strains by utilizing specific primers for the genes that code for the antibiotic resistant mechanisms as well as with primers for the genes that code for virulence factors of $E$. coli.

\section{Conclusions}

The (GTG) $)_{5}$ PCR based co-clustering analysis indicated that the clinical isolates had a closer relationship to iguana E. coli isolates than to fresh and marine water isolates. However, in accordance with the BOX, clinical isolates were most similar to marine, followed by freshwater and iguanas. The DNA barcoding allowed for the tracing of the evolution and relatedness of $E$. coli isolated from human urine with UTI and natural environments.

Unexpectedly, wide exogenous intraspecies diversity was documented for newly isolated organisms from variable natural habitats in Grenada which appeared to agree with the genomic variation observed with human $E$. coli isolates.

Similarity of UPEC to strains isolated from natural sources in Grenada indicated a possible epidemiological link of UPEC to a popular food source and to the anthropogenic water pollution in Grenada.

Antibiotic resistance patterns of the UTI strains with E. coli shared similarity with the isolates from freshwater samples, followed by iguana and marine isolates.

\section{References}

[1] Pascal, S., Pena, M. and Blackman, K. (2013) Perceptions of Changes and Impacts Accompanying the Introduction of Management Planning to the Woburn/Clarke's Court Bay MPA, Grenada. 65th Gulf and Caribbean Fisheries Institute.

[2] Jancel, T. and Dudas, V. (2002) Management of Uncomplicated Urinary Tract Infections. Western Journal of Medicine, 176, 51-55. http://dx.doi.org/10.1136/ewjm.176.1.51

[3] Emody, L., Kerenyi, M. and Nagy, G. (2003) Virulence Factors of Uropathogenic Escherichia coli. International Journal of Antimicrobial Agents, 22, 29-33. http://dx.doi.org/10.1016/S0924-8579(03)00236-X 
[4] Scheutz, F. and Strockbine, N.A. and Genus, I. (2005) Escherichia Castellani and Chalmers in Bergey’s Manual of Systematic Bacteriology. Brenner, D. J., et al., Eds., Springer Inc., New York, 607-623.

[5] Ronald, A. (2002) The Etiology of Urinary Tract Infection: Traditional and Emerging Pathogens. The American Journal of Medicine, 113, 14S-19S. http://dx.doi.org/10.1016/S0002-9343(02)01055-0

[6] Manges, A.R. and Johnson, J.R. (2012) Food-Borne Origins of Escherichia coli Causing Extraintestinal Infections. Clinical Infectious Diseases, 55, 712-719. http://dx.doi.org/10.1093/cid/cis502

[7] Neu, H.C. (1992) Optimal Characteristics of Agents to Treat Uncomplicated Urinary Tract Infections. Infection, 20, S266-S271. http://dx.doi.org/10.1007/BF01710012

[8] Luthje, P. and Brauner, A. (2010) Putative Link between The Virulence-Associated fluA Gene and Fluoroquinolone Resistance in Uropathogenic Escherichia coli. Journal of Clinical Microbiology, 48, 675-676. http://dx.doi.org/10.1128/JCM.01443-09

[9] Ibekwe, A.M., Murinda, S.E. and Graves, A.K. (2011) Genetic Diversity and Antimicrobial Resistance of Escherichia coli from Human and Animal Sources Uncovers Multiple Resistances from Human Sources. PLoS One, 6, e20819. http://dx.doi.org/10.1371/journal.pone.0020819

[10] WHO (2014) Antimicrobial Resistance: Global Report on Surveillance 2014. WHO, Geneva.

[11] Dobrindt, U. (2005) (Patho-)Genomics of Escherichia coli. International Journal of Medical Microbiology, 295, 357371. http://dx.doi.org/10.1016/j.ijmm.2005.07.009

[12] Caugant, D.A., Levin, B.R. and Selander, R.K. (1981) Genetic Diversity and Temporal Variation in the E. coli Population of a Human Host. Genetics, 98, 467-490.

[13] Chen, S.L., et al. (2013) Genomic Diversity and Fitness of E. coli Strains Recovered from the Intestinal and Urinary Tracts of Women with Recurrent Urinary Tract Infection. Science Translational Medicine, 5, 184ra60. http://dx.doi.org/10.1126/scitranslmed.3005497

[14] Manges, A.R., et al. (2008) Endemic and Epidemic Lineages of Escherichia coli That Cause Urinary Tract Infections. Emerging Infectious Diseases, 14, 1575-1583. http://dx.doi.org/10.3201/eid1410.080102

[15] Santos, T., et al. (2013) Dissemination of Antibiotic Resistant Enterococcus spp. and Escherichia coli from Wild Birds of Azores Archipelago. Anaerobe, 24, 25-31. http://dx.doi.org/10.1016/j.anaerobe.2013.09.004

[16] Sylvester, W.R., et al. (2013) Prevalence, Serovars and Antimicrobial Susceptibility of Salmonella spp. from Wild and Domestic Green Iguanas (Iguana iguana) in Grenada, West Indies. Zoonoses Public Health, 61, 436-441.

[17] Farmer, 3rd, J.J., et al. (1985) Biochemical Identification of New Species and Biogroups of Enterobacteriaceae Isolated from Clinical Specimens. Journal of Clinical Microbiology, 21, 46-76.

[18] OXOID (2006) Culture Media. In: Bridson, I.E.Y., Ed., The OXOID Manual, OXOID Limited, Hampshire, 1-412.

[19] Kotelnikova, S. (2009) Environmental Testing Unit 2009. Microbiobogy Department, School of Medicine, St. George’s University, St. George's, 1-22.

[20] Holmes, B., Willcox, W.R. and Lapage, S.P. (1978) Identification of Enterobacteriaceae by the API 20E System. Journal of Clinical Pathology, 31, 22-30. http://dx.doi.org/10.1136/jcp.31.1.22

[21] MacFaddin, J.F. (2000) Biochemical Tests for Identification of Medical Bacteria. 3rd Edition, Lippincott Williams \& Wilkins, Philadelphia.

[22] Difco, L. (1998) Culture Media and Ingredients, Dehydrated. Difco Manual 1998, Division of Becton Dickinson and Company, Maryland, 19-585.

[23] Versalovic, J., Schneider, G.M., de Bruijn, F.J. and Lupski, J.R. (1994) Genomic Fingerprinting of Bacteria Using Repetitive Sequence Based Polymerase Chain Reaction. Methods in Molecular and Cellular Biology, 5, 25-40.

[24] Rademaker, J.L.W. and De Bruijn, F.J. (1997) Characterization and Classification of Microbes by Rep-PCR Genomic Fingerprinting and Computer Assisted Pattern Analysis. In: Caetano-Anollés, G. and Gresshoff, P.M., Eds., DNA Markers: Protocols, Applications and Overviews, John Wiley \& Sons, Hoboken, 151-171.

[25] Mohapatra, B.R., Broersma, K. and Mazumder, A. (2007) Comparison of Five Rep-PCR Genomic Fingerprinting Methods for Differentiation of Fecal Escherichia coli from Humans, Poultry and Wild Birds. FEMS Microbiology Letters, 277, 98-106. http://dx.doi.org/10.1111/j.1574-6968.2007.00948.x

[26] Garcia-Vallve, S., Palau, J. and Romeu, A. (1999) Horizontal Gene Transfer in Glycosyl Hydrolases Inferred from Codon Usage in Escherichia coli and Bacillus subtilis. Molecular Biology and Evolution, 16, 1125-1134. http://dx.doi.org/10.1093/oxfordjournals.molbev.a026203

[27] Rambaut, A. (2010) FigTree v1.3.1. Institute of Evolutionary Biology, University of Edinburgh, Edinburgh. http://tree.bio.ed.ac.uk/software/figtree/

[28] Hudzicki, J. (2010) Kirby-Bauer Disk Diffusion Susceptibility Test Protocol [Electronic Version]. 1-24. 
[29] Jorgensen, J.H., Turnidge, J.D. and Washington, J.A. (1999) Antibacterial Susceptibility Tests: Dilution and Disk Diffusion Methods. In: Versalovic, J., Ed., Manual of Clinical Microbiology, American Society for Microbiology, Washington DC.

[30] Drew, R. (2014) Dosing and Administration of Parenteral Aminoglycosides. http://www.uptodate.com/contents/dosing-and-administration-of-parenteral-aminoglycosides?source=search_result\&se arch=gentamicin\&selectedTitle=5 145\#H26719697

[31] Finlay, J. (2012) Management Plan for Woburn Clarke’s Court Bay Marine Protected Area. Grenada.

[32] Kariuki, S., Gilks, C., Kimari, J., Muyodi, J., Waiyaki, P. and Hart, C.A. (1999) Analysis of Salmonella enterica Serotype Typhimurium by Phage Typing, Antimicrobial Susceptibility and Pulsed-Field Gel Electrophoresis. Journal of Medical Microbiology, 48, 1037-1042. http://dx.doi.org/10.1099/00222615-48-11-1037

[33] Carson, C.A., Shear, B.L., Ellersieck, M.R. and Asfaw, A. (2001) Identification of Fecal Escherichia coli from Humans and Animals by Ribotyping. Applied and Environmental Microbiology, 67, 1503-1507. http://dx.doi.org/10.1128/AEM.67.4.1503-1507.2001

[34] Carson, C.A., Shear, B.L., Ellersieck, M.R. and Schnell, J.D. (2003) Comparison of Ribotyping and Repetitive Extragenic Palindromic-PCR for Identification of Fecal Escherichia coli from Humans and Animals. Applied and Environmental Microbiology, 69, 1836-1839. http://dx.doi.org/10.1128/AEM.69.3.1836-1839.2003

[35] Bernhard, A.E. and Field, K.G. (2000) Identification of Nonpoint Sources of Fecal Pollution in Coastal Waters by Using Host-Specific 16S Ribosomal DNA Genetic Markers from Fecal Anaerobes. Applied and Environmental Microbiology, 66, 1587-1594. http://dx.doi.org/10.1128/AEM.66.4.1587-1594.2000

[36] Dombek, P.E., Johnson, L.K., Zimmerley, S.T. and Sadowsky, M.J. (2000) Use of Repetitive DNA Sequences and the PCR to Differentiate Escherichia coli Isolates from Human and Animal Sources. Applied and Environmental Microbiology, 66, 2572-2577. http://dx.doi.org/10.1128/AEM.66.6.2572-2577.2000

[37] Vincent, C., Boerlin, P., Daignault, D., Dozois, C.M., Dutil, L., Galanakis, C., et al. (2010) Food Reservoir for Escherichia coli Causing Urinary Tract Infections. Emerging Infectious Diseases, 16, 88-95. http://dx.doi.org/10.3201/eid1601.091118

[38] Kon, T., Weir, S.C., Howell, E.T., Lee, H. and Trevors, J.T. (2009) Repetitive Element (REP)-Polymerase Chain Reaction (PCR) Analysis of Escherichia coli Isolates from Recreational Waters of Southeastern Lake Huron. Canadian Journal of Microbiology, 55, 269-276. http://dx.doi.org/10.1139/W08-123

[39] Amadi, V. (2012) Occurrence of Antibiotic-Resistant Fecal Indicators in Coastal Waters of Southern Grenada. St George's University, St George's.

[40] Amadi, V., Dolphin, G., Gue, R., Graff, S. and Kotelnikova Giesler, S.V. (2012) Tropical Beach Waters Harbor Resistant Bacterial Indicators: Escherichia coli Presented Similar Antibiotic Resistance Patterns to Uropathogenic Isolates. 3rd ASM Conference on Antimicrobial Resistance in Zoonotic Bacteria and Foodborne Pathogens in Animals, Humans and the Environment, Aix-en-Provence, France.

[41] van Elsas, J.D., Semenov, A.V., Costa, R. and Trevors, J.T. (2011) Survival of Escherichia coli in the Environment: Fundamental and Public Health Aspects. The ISME Journal, 5, 173-183. http://dx.doi.org/10.1038/ismej.2010.80

[42] Vignaroli, C., Luna, G.M., Rinaldi, C., Di Cesare, A., Danovaro, R. and Biavasco, F. (2012) New Sequence Types and Multidrug Resistance among Pathogenic Escherichia coli Isolates from Coastal Marine Sediments. Applied and Environmental Microbiology, 78, 3916-3922. http://dx.doi.org/10.1128/AEM.07820-11

[43] Kotelnikova, S. and Amadi, V. (2012) Exposure Risks and Frequencies of Drug Resistant Bacterial Indicators in Oceanic Tropical Waters of Grenada. In: WINDREF Annual Report 2012, Winward Islands Research \& Education Foundation, St. George’s University, St. George’s, 38-41.

[44] Patel, R.H., Pedersen, K. and Kotelnikova, S. (2010) The Bacteriological Analysis and Health Risks in the Urban Estuary of St. George’s Bay, Grenada, West Indies. Journal of Environmental Health, 73, 22-26.

[45] Moreno, E., Prats, G., Sabaté, M., Pérez, T., Johnson, J.R. and Andreu, A. (2006) Quinolone, Fluoroquinolone and Trimethoprim/Sulfamethoxazole Resistance in Relation to Virulence Determinants and Phylogenetic Background among Uropathogenic Escherichia coli. Journal of Antimicrobial Chemotherapy, 57, 204-211. http://dx.doi.org/10.1093/jac/dki468

[46] Okesola, A.O. and Aroundegbe, T.I. (2011) Antibiotic Resistance Pattern of Uropathogenic Escherichia coli in South West Nigeria. African Journal of Medicine and Medical Sciences, 40, 235-238.

[47] Vieira, R.H., Carvalho, E.M.R., Carvalho, F.C.T., Silva, C.M., Sousa, O.V. and Rodrigues, D.P. (2010) Antimicrobial Susceptibility of Escherichia coli Isolated from Shrimp (Litopenaeus vannamei) and Pond Environment in Northeastern Brazil. Journal of Environmental Science and Health, Part B: Pesticides, Food Contaminants, and Agricultural Wastes, 45, 198-203. http://dx.doi.org/10.1080/03601231003613526

[48] Veldman, K., van Tulden, P., Kant, A., Testerink, J. and Mevius, D. (2013) Characteristics of Cefotaxime-Resistant 
Escherichia coli from Wild Birds in the Netherlands. Applied and Environmental Microbiology, 79, 7556-7561. http://dx.doi.org/10.1128/AEM.01880-13

[49] Radhouani, H., Poeta, P., Igrejas, G., Gonçalves, A., Vinué, L. and Torres, C. (2009) Antimicrobial Resistance and Phylogenetic Groups in Isolates of Escherichia coli from Seagulls at the Berlengas Nature Reserve. Veterinary Record, 165, 138-142. http://dx.doi.org/10.1136/vr.165.5.138 